\title{
HIGH LEVELS OF GENETIC VARIATION AS DETECTED BY AFLP IN Sideritis tmolea FROM WESTERN TURKEY
}

\author{
Seda NEMLI ${ }^{1}$, Umit SUBASI ${ }^{2}$, Volkan EROGLU⿱2${ }^{2}$, Serdar Gokhan SENOL ${ }^{2}$, \\ Muhammed Bahattin TANYOLAC ${ }^{* 1}$ \\ ${ }^{1}$ Department of Bioengineering, Ege University, Bornova-Izmir, TURKEY \\ ${ }^{2}$ Botanical Garden \& Herbarium Research and Application Center, \\ Ege University, Bornova-Izmir, TURKEY \\ Corresponding author: bahattin.tanyolac@ege.edu.tr
}

Received: 04.07.2014

\begin{abstract}
The objective of this study was to evaluate the level of genetic diversity among $29 \mathrm{~S}$. tmolea genotypes collected from Bozdag, Turkey, using the Amplified Fragment Length Polymorphism (AFLP) technique. A total of 392 AFLP markers were detected using 14 primer combinations. The number of polymorphic bands per AFLP primer combination ranged from 16 to 42 , with an average of 28 . The Polymorphism Information Content (PIC) values varied from 0.25 (M-CTC/E-AGC) to 0.72 (M-CAC/E-AAG) among 14 selective primers. The genetic dissimilarity that was detected using the NTSYS-PC software ranged from 0.09 to 0.82 . According to the dissimilarity results, a high level of genetic diversity existed among the studied genotypes. A model-based structural analysis revealed the presence of 2 populations. The defined population structure was helpful when studying the $S$. tmolea genotypes for diversity and classification.
\end{abstract}

Keywords: AFLP, genetic diversity, population structure, Sideritis tmolea

\section{INTRODUCTION}

Sivri çay (Sideritis tmolea L.) belongs to the Lamioideae (Stachyoideae) subfamily (Ryding, 1994; Hickey and King, 1997). Although taxa belonging to Lamiaceae Lindl. (Labiatae Juss.) are spread over a large area in habitat ranging from the North Pole to the Himalayas and from South eastern Asia to Hawaii, Australia, Africa and America, they are mainly distributed in the Mediterranean basin (Heywood, 1996). This family, which has 224 types and almost 5600 species, is divided into eight subfamilies according to Cantinoya. Sideritis L. is distributed especially in Mediterranean basin, is represented by more than 150 species in a wide area from the Bahamas to China and from Germany to Morocco and is divided into two subgenera. While Lamiaceae in the flora of Turkey is represented by 565 genera and 735 taxa (Guner et al., 2000), Sideritis is represented by 3 sections: Hesiodia (Moench) Bentham, Burgsdorfia (Moench) Briquet and Empedoclia (Rafin) Bentham. In Turkey, according to Duman (2013), Sideritis is represented by 53 taxa belonging to 45 species. While 40 of these taxa are endemic, the endemism ratio is approximately $75 \%$. In Turkey, there are 31 Sideritis taxa, of which 25 are endemic and used in domestic and foreign trade, as well as S. sipylea, S. tmolea and S. trojona, which are endemic and among the first 50 species that are in the danger of extinction due to unconscious collecting (Ozhatay et al., 1998).

There are a number of studies of the pharmaceutical compounds in Sideritis species and these studies especially have focused on essential oils, diterpenes and flavonoids (Akcos et al., 1999; Kirimer et al., 2001; Topcu et al., 2002). Various anti-inflammatory, analgesic, diuretical, antiulcer, antidepressant, antimicrobial and insect repellent effects of Sideritis species that are grown in Turkey have been studied (Ozturk et al., 1996; Akcos et al., 1999; Bondi et al., 2000). Sideritis species have an important place among other plants both as an herbal tea and household remedy. While Sideritis species are known under various names in Anatolia, they are usually referred to as "Mountain Tea", "Plateau Tea" and "Sage". $S$. tmolea is known as "Acute Tea".

An analysis of genetic variation between individuals within a species or between different species or populations is useful in identifying the level of genetic variation (Brummer et al., 1995). These diversity studies provide useful information for understanding the genetic bases of various gene pools, for describing and conserving their germplasm and for correctly identifying the varieties in facilitating the selection of sources for new genes for improved yield and quality improvements (Cho et al., 2008). Traditionally, morphological traits, karyotypes and protein and isozyme markers have been widely used to 
assess genetic diversity (Mudibu et al., 2011). Therefore, the measurement of genetic variation based on morphological characteristics is time-consuming and incoherent and requires extensive field trials and evaluation (Astarini et al., 2004). Different DNA techniques (RFLP, RAPD, AFLP, SSR, CAPS, ISSR and SNP) that are not affected by the environment (Maciel et al., 2003) are necessary for genetic screening among categories of closely related species in germplasm banks (Lapitan et al., 2007). The major applications of DNA markers for plant genetics include the assessment of phylogeny in selecting suitable parents for the generation of heterosis (Biton et al., 2012). Thus, several researchers have developed a wide range of molecular markers that have been used in several genetic diversity studies (Shimomura and Hirashima, 2006; Martins-Lopes et al., 2008; Cui et al., 2010). Among the different molecular marker approaches, AFLP is one of the most widely used in various plant species with different degrees of relatedness (Witkowicz et al., 2003). AFLP is suitable for studying diversity. The AFLP technique is based on the amplification of short restriction endonuclease-digested genomic DNA fragments onto which adaptors have been ligated at both ends using Polymerase Chain reaction (PCR) (Saiki et al., 1988). The presence or absence of these selective nucleotides in the genomic fragments being amplified provides the polymorphism. Alternately, the AFLP technique relies on a system of dominant markers that allow for the simultaneous analysis of a large number of markers in the genome. This method is highly reproducible and can be used to survey the overall genetic differences in the nuclear genome in a single assay without the need for primary sequence knowledge to design primers (Vuylsteke et al., 1999).

The objective of this research was to investigate the level of molecular diversity and phylogenetic relationships at the AFLP marker level among epidemic Sideritis that were collected from Bozdag.

\section{MATERIALS AND METHODS}

\section{The collected $S$. tmolea species}

The material of the current study is S. tmolea P.H. Davis by Lamiaceae. S. tmolea is distributed on the West side of Bozdag and on the slopes of the North and Northwest sides of Kangal Mount, which is a part of Bozdağlar at an altitude of 1450-2100 m. DNA samples were collected from the Bozdag Mountains; a population of individuals from different points was sampled in at least 10 - $\mathrm{m}$ intervals and GPS data for all of the samples was recorded (Table 1).

Table 1. Geographic distribution of $S$. tmolea landraces sampled in this study.

\begin{tabular}{|c|c|c|c|c|c|}
\hline Genotype number & Altitude (m*) & GPS* & Genotype number & Altitude $\left(\mathrm{m}^{*}\right)$ & GPS* \\
\hline 1 & 1654 & $\begin{array}{l}38^{\circ} 16^{\prime} 06^{\prime \prime} \mathrm{N}^{*} \\
028^{\circ} 04^{\prime} 52^{\prime \prime} \mathrm{E}^{*}\end{array}$ & 16 & 1564 & $\begin{array}{c}38^{\circ} 201^{\prime} 14^{\prime \prime} \mathrm{N} \\
028^{\circ} 07^{\prime} 22^{\prime \prime} \mathrm{E}\end{array}$ \\
\hline 2 & 1695 & $\begin{array}{l}38^{\circ} 19^{\prime} 12^{\prime \prime} \mathrm{N} \\
028^{\circ} 04^{\prime} 58^{\prime \prime} \mathrm{E}\end{array}$ & 17 & 1615 & $\begin{array}{l}38^{\circ} 20^{\prime} 12^{\prime \prime} \mathrm{N} \\
028^{\circ} 07^{\prime} 21^{\prime \prime} \mathrm{E}\end{array}$ \\
\hline 3 & 1747 & $\begin{array}{l}38^{\circ} 19^{\prime} 16^{\prime \prime} \mathrm{N} \\
028^{\circ} 04^{\prime} 58^{\prime \prime} \mathrm{E}\end{array}$ & 18 & 1566 & $\begin{array}{l}38^{\circ} 20^{\prime} 47^{\prime \prime} \mathrm{N} \\
028^{\circ} 08^{\prime} 27^{\prime \prime} \mathrm{E}\end{array}$ \\
\hline 4 & 1651 & $\begin{array}{l}38^{\circ} 19^{\prime} 44^{\prime \prime} \mathrm{N} \\
028^{\circ} 06^{\prime} 53^{\prime \prime} \mathrm{E}\end{array}$ & 19 & 1566 & $\begin{array}{l}38^{\circ} 20^{\prime} 47^{\prime \prime} \mathrm{N} \\
028^{\circ} 08^{\prime} 27^{\prime \prime} \mathrm{E}\end{array}$ \\
\hline 5 & 1703 & $\begin{array}{l}38^{\circ} 19^{\prime} 37^{\prime \prime} \mathrm{N} \\
028^{\circ} 06^{\prime} 49^{\prime \prime} \mathrm{E}\end{array}$ & 20 & 1555 & $\begin{array}{l}38^{\circ} 20^{\prime} 49^{\prime \prime} \mathrm{N} \\
028^{\circ} 08^{\prime} 27^{\prime \prime} \mathrm{E}\end{array}$ \\
\hline 6 & 1857 & $\begin{array}{l}38^{\circ} 19^{\prime} 29^{\prime \prime} \mathrm{N} \\
028^{\circ} 06^{\prime} 42^{\prime \prime} \mathrm{E}\end{array}$ & 21 & 1980 & $\begin{array}{l}38^{\circ} 19^{\prime} 27^{\prime \prime} \mathrm{N} \\
028^{\circ} 05^{\prime} 39^{\prime \prime} \mathrm{E}\end{array}$ \\
\hline 7 & 1967 & $\begin{array}{l}38^{\circ} 19^{\prime} 26^{\prime \prime} \mathrm{N} \\
028^{\circ} 06^{\prime} 23^{\prime \prime} \mathrm{E}\end{array}$ & 22 & 1960 & $\begin{array}{l}38^{\circ} 01^{\prime} 24^{\prime \prime} \mathrm{N} \\
028^{\circ} 05^{\prime} 36^{\prime \prime} \mathrm{E}\end{array}$ \\
\hline 8 & 1967 & $\begin{array}{l}38^{\circ} 19^{\prime} 26^{\prime \prime} \mathrm{N} \\
028^{\circ} 06^{\prime} 23^{\prime \prime} \mathrm{E}\end{array}$ & 23 & 1960 & $\begin{array}{l}38^{\circ} 01^{\prime} 24^{\prime \prime} \mathrm{N} \\
028^{\circ} 05^{\prime} 36^{\prime \prime} \mathrm{E}\end{array}$ \\
\hline 9 & 1709 & $\begin{array}{l}38^{\circ} 19^{\prime} 48^{\prime \prime} \mathrm{N} \\
028^{\circ} 06^{\prime} 30^{\prime \prime} \mathrm{E}\end{array}$ & 24 & 1920 & $\begin{array}{l}38^{\circ} 19^{\prime} 23^{\prime \prime} \mathrm{N} \\
028^{\circ} 05^{\prime} 29^{\prime \prime} \mathrm{E}\end{array}$ \\
\hline 10 & 1669 & $\begin{array}{l}38^{\circ} 19^{\prime} 40^{\prime \prime} \mathrm{N} \\
028^{\circ} 06^{\prime} 32^{\prime \prime} \mathrm{E}\end{array}$ & 25 & 1920 & $\begin{array}{l}38^{\circ} 19^{\prime} 23^{\prime \prime} \mathrm{N} \\
028^{\circ} 05^{\prime} 29^{\prime \prime} \mathrm{E}\end{array}$ \\
\hline 11 & 1597 & $\begin{array}{l}38^{\circ} 20^{\prime} 34^{\prime \prime} \mathrm{N} \\
028^{\circ} 06^{\prime} 34^{\prime \prime} \mathrm{E}\end{array}$ & 26 & 1786 & $\begin{array}{l}38^{\circ} 19^{\prime} 46^{\prime \prime} \mathrm{N} \\
028^{\circ} 07^{\prime} 20^{\prime \prime} \mathrm{E}\end{array}$ \\
\hline 12 & 1597 & $\begin{array}{l}38^{\circ} 20^{\prime} 34^{\prime \prime} \mathrm{N} \\
028^{\circ} 06^{\prime} 34^{\prime \prime} \mathrm{E}\end{array}$ & 27 & 1751 & $\begin{array}{l}38^{\circ} 19^{\prime} 48^{\prime \prime} \mathrm{N} \\
028^{\circ} 07^{\prime} 17^{\prime \prime} \mathrm{E}\end{array}$ \\
\hline 13 & 1641 & $\begin{array}{l}38^{\circ} 20^{\prime} 59^{\prime \prime} \mathrm{N} \\
028^{\circ} 05^{\prime} 47^{\prime \prime} \mathrm{E}\end{array}$ & 28 & 1664 & $\begin{array}{l}38^{\circ} 19^{\prime} 49^{\prime \prime} \mathrm{N} \\
028^{\circ} 07^{\prime} 12^{\prime \prime} \mathrm{E}\end{array}$ \\
\hline 14 & 1534 & $\begin{array}{l}38^{\circ} 21^{\prime} 19^{\prime \prime} \mathrm{N} \\
028^{\circ} 05^{\prime} 39^{\prime \prime} \mathrm{E}\end{array}$ & 29 & 1588 & $\begin{array}{l}38^{\circ} 19^{\prime} 52^{\prime \prime} \mathrm{N} \\
028^{\circ} 07^{\prime} 60^{\prime \prime} \mathrm{E}\end{array}$ \\
\hline 15 & 1534 & $\begin{array}{l}38^{\circ} 21^{\prime} 19^{\prime \prime} \mathrm{N} \\
028^{\circ} 05^{\prime} 39^{\prime \prime} \mathrm{E}\end{array}$ & & & \\
\hline
\end{tabular}




\section{DNA isolation}

The young leaves from Sideritis were ground to a fine powder with liquid nitrogen in a TissueLyser (Technogen Co. Izmir Turkey). The total genomic DNA was isolated according to the protocol of Doyle and Doyle (1987) with some modifications. The purified DNA was resuspended in $100 \mu \mathrm{L}$ of $10 \mathrm{mM}$ Tris- $\mathrm{HCl}(\mathrm{pH} 8.0)$ buffer containing $1 \mathrm{mM}$ EDTA for use in the analysis. The DNA concentration of the sample was determined spectrophotometrically by measuring the absorbance at 260 and $280 \mathrm{~nm}$ using a NanoDrop ND-1000 (Thermo Sci. Co) spectrophotometer and the quality was checked on $1 \%$ agarose gels. The stock DNA was diluted to a working solution of $200 \mathrm{ng} / \mu \mathrm{L}$ and the samples were stored at $-20^{\circ} \mathrm{C}$ for the $\mathrm{PCR}$ reactions.

\section{AFLP analysis}

An amplified fragment length polymorphism analysis was performed using the Li-Cor AFLP Kit (catalog number: 830-06195 AFLP2-DYE Selective Amplification Kit, Lincoln, NE, USA). followed the manufacturer's instructions. According to the kit, genomic DNA (200 $\mathrm{ng} / \mu \mathrm{L})$ was digested with the EcoRI and MseI restriction enzymes at $37^{\circ} \mathrm{C}$ for $2 \mathrm{~h}$ followed by $15 \mathrm{~min}$ at $70{ }^{\circ} \mathrm{C}$. The digested DNA fragments were then ligated with specific enzyme adaptors in the presence of T4 DNA ligase. A ligation reaction was performed at $37^{\circ} \mathrm{C}$ for $3 \mathrm{~h}$. Pre-amplification PCR was performed after diluting the ligated DNA ten-fold with double deionized water and then pre-amplifying using EcoRI and MseI non-selective primers with one additional selective nucleotide at the 3' end of the $M s e \mathrm{I}$ primer $(M s e \mathrm{I}+\mathrm{C})$ and the $E c o$ RI primer $(E c o$ RI $+\mathrm{A})$. The primer combinations were named according to the restriction enzyme initials, such as $\mathrm{M}$ CAC/E-GGA: "M" stands for MseI, "CAC" stands for the nucleotide extensions and "E" stands for the EcoRI enzyme. After the pre-selective PCR, the reaction mixture was diluted 1:40 and used as a template for selective amplification. Selective amplifications were performed with the selective primer combinations of EcoRI (labeled with two different fluorescent dyes (IRD 700 or 800) at the $5^{\prime}$ ends) and MseI (unlabeled) with three selective nucleotides. Fourteen primer combinations were used to screen for polymorphisms among the samples (Table 2). The AFLP products were separated electrophoretically in denaturing $8 \%$ polyacrylamide gels (19:1 ratio acrylamide:bisacrylamide, 7,5 $\mathrm{M}$ urea and $1 \mathrm{X}$ TBE buffer) at $45 \mathrm{~W}$ constant power for approximately $4 \mathrm{~h} 30 \mathrm{~min}$ and run on a Li-Cor 4300s DNA Analyzer. The size of the products was determined using the Li-Cor ${ }^{\circledR}$ IRDye $^{\circledR}$ as an internal size standard (50 to $700 \mathrm{bp}$ ). The imaging of the AFLP fragments was performed using the SAGA software.

Table 2. Number of polymorphic bands and PIC for each AFLP primer pair that was used in the analysis of the $29 S$. tmolea genotypes

\begin{tabular}{clcc}
\hline Primer Number & Primer Pairs & Number of polymorphic bands & PIC \\
\hline $\mathbf{1}$ & M-CAA / E-AAG & 19 & 0.54 \\
$\mathbf{2}$ & M-CAA / E-ACT & 20 & 0.56 \\
$\mathbf{3}$ & M-CAC / E-AAG & 19 & 0.72 \\
$\mathbf{4}$ & M-CAC / E-ACT & 23 & 0.57 \\
$\mathbf{5}$ & M-CTT / E-AAC & 31 & 0.41 \\
$\mathbf{6}$ & M-CTT / E-AGG & 29 & 0.34 \\
$\mathbf{7}$ & M-CTC / E-ACA & 23 & 0.42 \\
$\mathbf{8}$ & M-CTC / E-AGC & 16 & 0.25 \\
$\mathbf{9}$ & M-CTC / E-AAG & 27 & 0.43 \\
$\mathbf{1 0}$ & M-CTC / E-ACT & 22 & 0.39 \\
$\mathbf{1 1}$ & M-CTG / E-ACA & 40 & 0.56 \\
$\mathbf{1 2}$ & M-CTG / E-AGC & 41 & 0.52 \\
$\mathbf{1 3}$ & M-CTG / E-AAG & 42 & 0.64 \\
$\mathbf{1 4}$ & M-CTG / E-ACT & 40 & 0.48 \\
& TOTAL & $\mathbf{3 9 2}$ & $\mathbf{0 . 4 9}$ \\
\hline
\end{tabular}

\section{Data analysis}

The AFLP profiles were assessed individually for each primer pair combination. The polymorphic AFLP bands were manually scored as a binary data matrix with presence as " 1 " and absence as " 0 " across all of the 29 genotypes. Only the clear and strong bands were recorded and used for the analysis. Genetic dissimilarity estimates were calculated between the genotypes using Jaccard's coefficient of dissimilarity. The calculations and analyses were generated with the help of NTSYS-PC software version 2.02 (Rohlf, 1998). The PIC of each marker was calculated using PIC $=1-\Sigma \mathrm{pi}^{2}$, where $\mathrm{P}_{\mathrm{i}}$ is the band frequency of the $\mathrm{i}^{\text {th }}$ allele (Smith et al., 1997).

\section{Assessment of population structure with AFLP}

All of the AFLP markers that were developed in this study were used to infer the population structure in the set of 29 genotypes. For the analysis of population structure, we used the STRUCTURE version 2.3.4 software, which implements a Bayesian, model-based clustering algorithm (Pritchard et al., 2000). The individuals in the sample are 
assigned to populations (clusters) or jointly to additional populations if their genotypes indicate that the populations are admixed. The optimal number of populations $(\mathrm{K})$ was determined under a burn-in period of 100,000 with 100,000 Markov Chain Monte Carlo iterations. The membership of each genotype was run for the range of genetic clusters from value of $K=1$ to 10 with the admixture model and for each $\mathrm{K}$, the run was replicated 10 times. For each $\mathrm{K}$ value, the runs showing the highest posterior probability of data were considered. The true value of $\mathrm{K}$ and the number of populations were detected by an ad hoc quantity based on the second order rate of change of the likelihood function with respect to $\mathrm{K}(\Delta \mathrm{K})$ (Evanno et al., 2005).

\section{RESULTS AND DISCUSSION}

In the current study, we detected the genetic diversity and phylogenetic relationships of $S$. tmolea at the AFLP marker level. The size range between the smallest and largest alleles that were observed for a given AFLP varied from 50 to $500 \mathrm{bp}$, which was able to discriminate between the 29 Sideritis genotypes. Similar results were observed by Murtaza (2006) and Strikic et al. (2010), who found band sizes ranging from 50 to 500 bp using cotton and olive genotypes, respectively. AFLP marker systems were highly effective in discriminating the $29 \mathrm{~S}$. tmolea genotypes that were analyzed. The total number of assays included 14 primer combinations for AFLP, as listed in Table 2. In total, the 14 selective primer combinations amplified 392 polymorphic products for the 29 analyzed genotypes (Table 2). Previously, AFLP marker systems were used to characterize various genotypes (Maras et al., 2008; Strikic et al., 2010; Nemli, 2013; Panahi et al., 2013). For example, Grati-Kamoun et al. (2006) found 172 polymorphic bands from 9 primer combinations in olive genotypes. Khalighi et al. (2008) obtained 387 bands from 14 primer combinations. Colomba and Gregorini (2011) studied durum wheat using 8 AFLP primer pairs that generated 137 amplification products and 17 polymorphic bands per primer combination. Farah Fazwa et al. (2013) detected a total of 170 AFLP fragments among 62 accessions for two varieties of $L$. pumila ( $L$. pumila var. pumila and L. pumila var. alata). From the studies that are mentioned above, the authors concluded that AFLP was a very sensitive technique for detecting markers for genetic studies. Based on the results of our study, 14 AFLP primer pairs amplified in the $29 \mathrm{~S}$. tmolea genotypes from Turkey, the number of polymorphic bands was higher than that of previous studies (Colomba and Gregorini, 2011; Farah Fazwa et al., 2013). These findings indicate a high level of genetic variation among the studied genotypes. The number of polymorphic bands per AFLP primer combination ranged from 16 (M-CTC / EAGC) to 42 (M-CTG / E-AAG). On average, 28 polymorphic bands were amplified by each primer combination (Table 2). These results are similar to those of this study in terms of the average number of scored polymorphic bands. Khalighi et al. (2008) found the average number of 27 in Triticum spp. and Aegilops spp. and Zhang et al. (2012) reported 31 polymorphic bands per primer combination from their AFLP study in Brachypodium species.

The PIC is defined as the probability that two alleles that are taken at random from a population can be distinguished using the marker in question and is a measure of allele diversity at a locus. The success of AFLP markers in a variety of genotypes that were corrected with the PIC value indicates the genetic variation among the genotypes (Muse et al., 2005). The PIC was calculated to identify the most informative AFLP primers. The PIC value ranged from 0,25 (M-CTC / EAGC) to 0,72 (M-CAC / E-AAG) among the 14 selective primers. The average PIC was calculated as 0,49 , demonstrating the good discriminatory power of the identified markers (Table 2). Furthermore, except for MCTC/E-AGC (PIC value: 0,25), all of the AFLP combinations were highly informative, with an average PIC of 0.6 (Table 2). However, higher mean PIC values were obtained by AFLP markers compared to those of other studies, such as Yuan et al. (2011) $(0,33)$ and Zhang et al. (2012). Pecina-Quintero et al. (2012) reported a mean PIC value of 0,294 with 10 primer combinations using 41 genotypes of the sweet sorghum germplasm. The same AFLP markers were used by Pecina-Quintero et al. (2012) to produce a lower PIC value $(0,27)$ for the $\mathrm{M}$ CAC/E-AAG and M-CTG/E-ACA primer combinations. However, in this study, the PIC values were 0,72 and 0,56 for the $\mathrm{M}-\mathrm{CAC} / \mathrm{E}-\mathrm{AAG}$ and $\mathrm{M}-\mathrm{CTG} / \mathrm{E}-\mathrm{ACA}$ primer combinations, respectively. Therefore, the AFLP combinations that were used in this study have a high discriminatory power and are recommended for use in genetic diversity analyses of S. tmolea.

Understanding the genetic similarity/dissimilarity among genotypes is crucial in germplasm collection and also facilitates the thorough utility of these genetic resources in crop improvement programs (Farah Fazwa et al., 2013). The genetic distance of the improved Sideritis genotypes is shown in Table 3 . The $0 / 1$ matrix was used to calculate the distance among the 29 Sideritis genotypes according to Jaccard (1908). The matrix of genetic dissimilarity ranged from 0,09 to 0,82 . Among these values, the highest degree of dissimilarity $(0,82)$ was found between genotypes 13 and 23 , indicating that these genotypes were the most distinct from each other. The lowest degree of dissimilarity $(0,09)$ that was revealed by the AFLP analysis was found between genotypes 27 and 28. In this study, a higher AFLP polymorphism was observed among the genotypes than in several previous reports using AFLP markers. The genetic distance values demonstrated a large genetic variation among the studied genotypes in a narrow geographic region. A high level of genetic variation was found among the genotypes that may be attributed to habitat fragmentation due to anthropopression, geographic isolation and genetic drift (Qian et al., 2013). Similarly, Cinar et al. (2009) used 8 Sideritis species for genotyping and reported that the genetic distance varied from 0,284 (between Sideritis arguta 1370 and Sideritis arguta 778) to 0,903 (between 
Table 3. Genetic dissimilarity coefficient matrices of the 29 genotypes of $S$. tmolea using AFLP markers (Jaccard's coefficient)

\begin{tabular}{|c|c|c|c|c|c|c|c|c|c|c|c|c|c|c|c|c|c|c|c|c|c|c|c|c|c|c|c|c|c|}
\hline Genotype number & 01 & 02 & 03 & 04 & 05. & 06 & 07 & 08 & 09 & 10 & 11 & 12 & 13 & 14 & 15 & 16 & 17 & 18 & 19 & 20 & 21 & 22 & 23 & 24 & 25 & 26 & 27 & 28 & 29 \\
\hline 01 & 0.00 & & & & & & & & & & & & & & & & & & & & & & & & & & & & \\
\hline 02 & 0.29 & 0.00 & & & & & & & & & & & & & & & & & & & & & & & & & & & \\
\hline 03 & 0.40 & 0.23 & 0.00 & & & & & & & & & & & & & & & & & & & & & & & & & & \\
\hline 04 & 0.48 & 0.59 & 0.56 & 0.00 & & & & & & & & & & & & & & & & & & & & & & & & & \\
\hline 05 & 0.33 & 0.49 & 0.49 & 0.36 & 0.00 & & & & & & & & & & & & & & & & & & & & & & & & \\
\hline 06 & 0.33 & 0.24 & 0.26 & 0.46 & 0.45 & 0.00 & & & & & & & & & & & & & & & & & & & & & & & \\
\hline 07 & 0.31 & 0.24 & 0.30 & 0.49 & 0.44 & 0.23 & 0.00 & & & & & & & & & & & & & & & & & & & & & & \\
\hline 08 & 0.55 & 0.50 & 0.45 & 0.52 & 0.42 & 0.43 & 0.45 & 0.00 & & & & & & & & & & & & & & & & & & & & & \\
\hline 09 & 0.40 & 0.35 & 0.39 & 0.48 & 0.36 & 0.36 & 0.40 & 0.41 & 0.00 & & & & & & & & & & & & & & & & & & & & \\
\hline 10 & 0.43 & 0.47 & 0.56 & 0.46 & 0.45 & 0.47 & 0.44 & 0.56 & 0.36 & 0.00 & & & & & & & & & & & & & & & & & & & \\
\hline 11 & 0.52 & 0.33 & 0.39 & 0.71 & 0.62 & 0.41 & 0.43 & 0.51 & 0.34 & 0.44 & 0.00 & & & & & & & & & & & & & & & & & & \\
\hline 12 & 0.45 & 0.30 & 0.35 & 0.67 & 0.55 & 0.35 & 0.37 & 0.51 & 0.32 & 0.37 & 0.15 & 0.00 & & & & & & & & & & & & & & & & & \\
\hline 13 & 0.56 & 0.37 & 0.39 & 0.71 & 0.62 & 0.41 & 0.44 & 0.56 & 0.39 & 0.45 & 0.11 & 0.18 & 0.00 & & & & & & & & & & & & & & & & \\
\hline 14 & 0.56 & 0.40 & 0.41 & 0.71 & 0.63 & 0.43 & 0.45 & 0.56 & 0.39 & 0.47 & 0.14 & 0.21 & 0.11 & 0.00 & & & & & & & & & & & & & & & \\
\hline 15 & 0.41 & 0.45 & 0.47 & 0.60 & 0.50 & 0.44 & 0.44 & 0.51 & 0.35 & 0.33 & 0.31 & 0.29 & 0.34 & 0.34 & 0.00 & & & & & & & & & & & & & & \\
\hline 16 & 0.51 & 0.34 & 0.40 & 0.73 & 0.64 & 0.44 & 0.40 & 0.44 & 0.44 & 0.45 & 0.16 & 0.21 & 0.18 & 0.22 & 0.32 & 0.00 & & & & & & & & & & & & & \\
\hline 17 & 0.47 & 0.37 & 0.43 & 0.69 & 0.58 & 0.43 & 0.44 & 0.53 & 0.41 & 0.45 & 0.16 & 0.20 & 0.18 & 0.18 & 0.31 & 0.13 & 0.00 & & & & & & & & & & & & \\
\hline 18 & 0.40 & 0.49 & 0.52 & 0.47 & 0.49 & 0.47 & 0.47 & 0.52 & 0.41 & 0.34 & 0.47 & 0.42 & 0.50 & 0.50 & 0.37 & 0.50 & 0.47 & 0.00 & & & & & & & & & & & \\
\hline 19 & 0.40 & 0.51 & 0.52 & 0.48 & 0.45 & 0.52 & 0.49 & 0.49 & 0.39 & 0.41 & 0.46 & 0.38 & 0.47 & 0.48 & 0.35 & 0.47 & 0.47 & 0.32 & 0.00 & & & & & & & & & & \\
\hline 20 & 0.50 & 0.58 & 0.63 & 0.56 & 0.58 & 0.61 & 0.52 & 0.65 & 0.52 & 0.44 & 0.53 & 0.46 & 0.55 & 0.52 & 0.42 & 0.57 & 0.52 & 0.38 & 0.37 & 0.00 & & & & & & & & & \\
\hline 21 & 0.49 & 0.68 & 0.72 & 0.45 & 0.44 & 0.64 & 0.57 & 0.58 & 0.60 & 0.49 & 0.79 & 0.66 & 0.81 & 0.80 & 0.54 & 0.77 & 0.72 & 0.49 & 0.38 & 0.44 & 0.00 & & & & & & & & \\
\hline 22 & 0.41 & 0.65 & 0.68 & 0.44 & 0.42 & 0.65 & 0.60 & 0.56 & 0.48 & 0.45 & 0.73 & 0.65 & 0.79 & 0.80 & 0.52 & 0.76 & 0.68 & 0.43 & 0.38 & 0.42 & 0.32 & 0.00 & & & & & & & \\
\hline 23 & 0.61 & 0.82 & 0.79 & 0.49 & 0.57 & 0.81 & 0.73 & 0.66 & 0.60 & 0.52 & 0.80 & 0.68 & 0.83 & 0.79 & 0.54 & 0.83 & 0.80 & 0.48 & 0.43 & 0.43 & 0.38 & 0.33 & 0.00 & & & & & & \\
\hline 24 & 0.45 & 0.47 & 0.47 & 0.56 & 0.51 & 0.49 & 0.45 & 0.62 & 0.43 & 0.42 & 0.39 & 0.38 & 0.42 & 0.44 & 0.40 & 0.45 & 0.41 & 0.43 & 0.44 & 0.42 & 0.50 & 0.45 & 0.56 & 0.00 & & & & & \\
\hline 25 & 0.49 & 0.42 & 0.49 & 0.65 & 0.56 & 0.44 & 0.41 & 0.55 & 0.42 & 0.41 & 0.31 & 0.32 & 0.33 & 0.35 & 0.33 & 0.28 & 0.28 & 0.41 & 0.45 & 0.51 & 0.63 & 0.60 & 0.71 & 0.29 & 0.00 & & & & \\
\hline 26 & 0.52 & 0.73 & 0.71 & 0.40 & 0.46 & 0.67 & 0.60 & 0.45 & 0.52 & 0.43 & 0.72 & 0.63 & 0.77 & 0.76 & 0.47 & 0.72 & 0.71 & 0.45 & 0.36 & 0.43 & 0.37 & 0.35 & 0.33 & 0.49 & 0.60 & 0.00 & & & \\
\hline 27 & 0.51 & 0.42 & 0.43 & 0.75 & 0.62 & 0.45 & 0.49 & 0.58 & 0.45 & 0.47 & 0.24 & 0.28 & 0.21 & 0.22 & 0.38 & 0.26 & 0.23 & 0.45 & 0.49 & 0.55 & 0.73 & 0.71 & 0.79 & 0.40 & 0.28 & 0.74 & 0.00 & & \\
\hline 28 & 0.52 & 0.38 & 0.43 & 0.75 & 0.61 & 0.46 & 0.49 & 0.52 & 0.47 & 0.48 & 0.25 & 0.30 & 0.25 & 0.26 & 0.41 & 0.28 & 0.26 & 0.48 & 0.49 & 0.57 & 0.73 & 0.72 & 0.81 & 0.46 & 0.33 & 0.70 & 0.10 & 0.00 & \\
\hline 29 & 0.48 & 0.42 & 0.49 & 0.52 & 0.52 & 0.45 & 0.44 & 0.57 & 0.40 & 0.37 & 0.34 & 0.32 & 0.37 & 0.35 & 0.34 & 0.41 & 0.33 & 0.38 & 0.41 & 0.42 & 0.59 & 0.55 & 0.61 & 0.38 & 0.38 & 0.53 & 0.31 & 0.33 & 0.00 \\
\hline
\end{tabular}


Sideritis perfoliata 20 and Sideritis perfoliata 47). These results indicate a high degree of genetic diversity among different species. We calculated a high degree of genetic diversity within $S$. tmolea samples that were collected in a narrow area of existing endemic species. Furthermore, the reproductive system directly influences the degree and distribution of genetic variation and can lead to reproductive isolation and eventually to speciation (Gonza'lez-Pe'rez et al., 2008). The level of total heterozygosity in outcrossing plants was higher than that from comparable analyses of self-pollinating plants (Nybom and Bartish, 2000). The high genetic diversity may be an indication that the number of individuals of this species was larger than previously studied (Prohens et al., 2007). The species in the genus Sideritis are distributed throughout the world and the distribution of these species could have once been much wider than it is currently, which could explain the high levels of genetic variation that were detected in this endemic species.
Twenty-nine Sideritis genotypes were analyzed in order to determine the population structure using the STRUCTURE. After running the $\mathrm{K}$ value, the curve peaked at $\Delta \mathrm{K}=2$ for the final analysis (Figure 1), indicating that the 2 population, namely Population 1 (red) and Population 2 (green), were the most capable of explaining the 29 Sideritis genotypes. Population 1 consists of 16 accessions (genotypes $1,4,5,6,7,8,9,10$, $18,19,20,21,22,23,24$ and 26) showed admixture levels at $1555,1703,1857$ and $1980 \mathrm{~m}$. The remaining 13 accessions from seemingly similar levels, ranging from 1500-1700 (m) except for genotype $25(1920 \mathrm{~m})$, were classified as Population 2 by the STRUCTURE version 2.3.4 software (Figure 1). The genotypes collected from same location did not form into one cluster. The differences among the genotypes may be explained by the assessment of certain morphological characteristics.
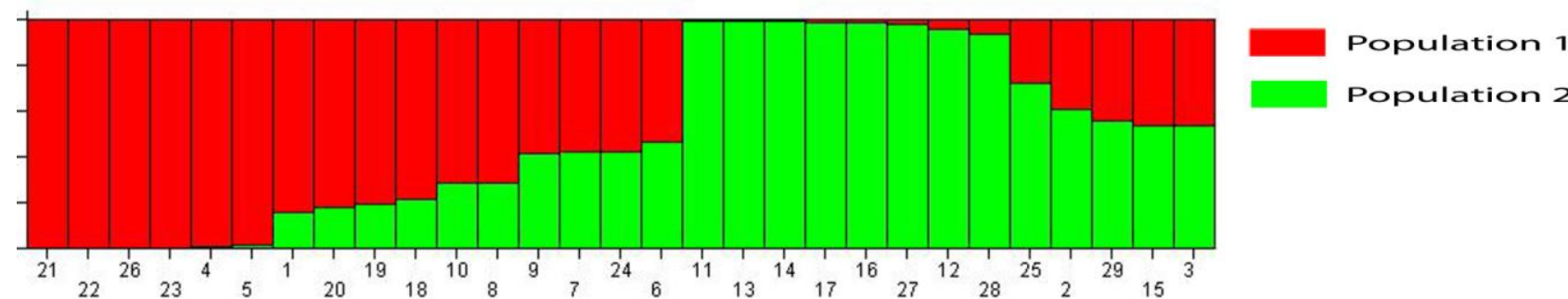

Figure 1. Bar plot showing the genetic diversity structure for the 29 S. tmolea genotypes using the program STRUCTURE version 2.3.4. Each population is represented by a different color as listed: red (POP1) and green (POP2).

In conclusion, the genus Sideritis provides a wide range of research possibilities due to its richness in compounds. This study is the first report of the use of the AFLP technique to evaluate the genetic relationships among $S$. tmolea genotypes and provides information on the population structure. A wide degree of genetic diversity is important for the characterization and development of improved varieties. Some Sideritis species are very difficult to distinguish morphologically due to lack of ecotype variation; therefore, this study demonstrates that the AFLP technique could play an important role in the identification of closely related taxa in Sideritis for future germplasm collection efforts in a cost-effective way. These preliminary results suggest that AFLP can be used in marker-assisted parental selection for future genetic diversity in genotypes while introgressing the desirable characters. The high levels of genetic variation that were observed between genotypes in $S$. tmolea indicate that management should aim to conserve as many of the small populations as possible in this study.

\section{ACKNOWLEDGEMENTS}

The authors would like to thank the Scientific and Technological Research Council of Turkey (TUBITAK Project No: 108T851) and the Ege University Science and Technology Centre (EBILTEM) for supporting this study (Project No: 2010BIL03).

\section{LITERATURE CITED}

Akcos, Y., N. Ezer, I. Calıs, R. Demirdamar, B.C. Tel. 1999. Polyphenolic compounds of Sideritis lycia and their antiinflammatory activity. Pharm Biol. 36: 1-5.

Astarini, A.I., A.J. Plummer, A.R. Lancaster and G. Yan. 2004. Fingerprinting of cauliflower cultivars using RAPD markers. Aust J Agri Res. 55: 112-124.

Baser, K.H.C., G. Honda and W. Miki. 1986. Herb Drugs and Herbalists in Turkey- Studia Culturae Islamicae 27, Institute for the Study of Languages and Cultures of Asia and Africa, Tokyo.

Biton, I., S. Shevtsov, O. Ostersetzer, Y. Mani, S. Lavee, B. Avidan and G. Ben-ari, 2012. Genetic relationships and hybrid vigour in olive (Olea europaea $\mathrm{L}$.) by Microsatellites. Plant Breeding. 131: 767-774.

Bondi, M.L., M. Bruno, F. Piozzi, K.H.C. Baser and M.S.J. Simmonds. 2000. Diversity and antifeedant activity of diterpenes from Turkish species of Sideritis. Biochem Sys Ecol. 28: 299-303.

Brummer, E.C., J.H. Bouton and G. Korchert. 1995. Analysis of annual Medicago species using RAPD markers. Genome. 38: 362-367.

Cho, G-T., J. Lee, J-K. Moon, M-S. Yoon, H-J. Baek, J-H. Kang, T-S. Kim and N-C. Paek. 2008. Genetic diversity and population structure of Korean soybean landrace [Glycine $\max ($ L.) Merr.]. J Crop Sci Biotech. 11(2): 83-90.

Cinar, A., S. Elmasulu, A.G. Ince, M. Karaca, A.N. Onus and K. Turgut. 2009. A suitable DNA marker technique (minisatellites) for Sideritis (Lamiaceae) genotyping studies. Acta Horticulturae. 826(1): 439-446.

Colomba, M.S. and A. Gregorini. 2011. Genetic diversity analysis of the durum wheat Graziella Ra, Triticum turgidum 
L. subsp. durum (Desf.) Husn. (Poales, Poaceae). Biodiversity Journal. 2(2): 73-84.

Cui, H., K.T. Moe, J.W. Chung, Y.I. Cho, G.A. Lee and Y.J. Park. 2010. Genetic diversity and population structure of rice accessions from South Asia using SSR markers. Korean Journal of Breeding Science. 42(1): 11-22.

Davis, P.H. 1978. Flora of Turkey and the East Aegean Islands. Vol. 6, Edinburgh.

Doyle, J.J. and J.L .Doyle. 1987. A rapid DNA isolation procedure for small quantities of fresh leaf tissue. Phytochem Bull. 19: 11-15.

Duman, H. 2013. Sideritis. ed. Güner, A., S. Aslan, T. Ekim, M. Vural and M.T. Babaç, Nezahat Gokyigit Botanik Bahçesi ve Flora Araştırmaları Derneği Yayını, Istanbul.

Evanno, G., S. Regnaut and Goudet, J. 2005. Detecting the number of clusters of individuals using the software STRUCTURE: A simulation study. Molecular Ecology. (14)8: 2611-2620.

Farah Fazwa, M.A., H. Siti Salwana, H. Maideen and O. Mohamad. 2013. An Assessment of Genetic Relationship Among Superior Accessions of Labisia Pumila Analized by Amplified Fragment Length Polymorphism (AFLP) Markers. Open Science Repository Agriculture. Online(open-access). doi:10.7392/Agriculture.70081945.

Grati-Kamoun, N., F. Lamy Mahmoud, A. Rebai, A. Gargouri, O. Panaud and A. Saar. 2006. Genetic diversity of Tunisian olive tree (Olea europaea L.) cultivars assessed by AFLP markers. Genet Resour Crop Ev. 53: 265-275.

Gonza'lez-Pe'rez, M., P.A Asosa and F.J. Batista. 2008. Genetic variation and conservation of the endangered endemic Anagyris latifolia Brouss. ex Willd. (Leguminosae) from the Canary Islands. Plant Syst Evol. doi 10.1007/s00606-0090146-Z.

Guner, A., N. Ozhatay, T. Ekim and K.H.C. Baser. 2000. Flora of Turkey and the East Aegean Islands. Edinburgh: Edinburgh University Press. 11(2): 35-37.

Heywood, V.H. 1996. Flowering Plant Of The World - BT Bastrford LTD, London, pp:239.

Hickey, M. and C. King. 1997. Common Families of Lowering Plants. Chambridge Univ. Press., England, pp: 119-127.

Jaccard, P. 1908. Nouvelles recherches sur la distribution florale. Bul. Soc. Vaudoise Sci. Nat. 44: 223-270.

Khalighi, M., A. Arzani and M.A. Poursiahbidi. 2008 Assessment of genetic diversity in Triticum spp. and Aegilops spp. using AFLP markers. Afri J Biotechn. 7(5): 546-552.

Kirimer, N., N. Tabanea and B. Demirci. et al. 2001. The essential oil of a new Sideritis species: Sideritis ozturkii. Chem Nat Compd. 37(3): 234-237.

Lapitan, V.C., D.S. Brar, T. Abe and E.D. Redona. 2007 Assessment of genetic diversity of Philippine rice carrying good quality traits using SSR markers. Breeding Sci. 57: 263-270.

Maciel, F.L., S. Echeverrigaray, L.T.S. Gerald and F.G. Grazziotin. 2003. Genetic relationships and diversity among Brazilian cultivars and landraces of common beans (Phaseolus vulgaris L.) revealed by AFLP markers. Genetic Resources and Crop Evolution. 50: 887-893.

Maras, M., J. Sustar-Vozlic, B. Javornik and V. Meglic. 2008. The efficiency of AFLP and SSR markers in genetic diversity estimation and gene pool classification of common bean (Phaseolus vulgaris L.). Acta Agric Slov. 91: 87-96.

Martins-Lopes, P.S., G.E. Santos and H. Guedes-Pinto. 2008. DNA markers for Portuguese olive oil fingerprinting. J Agric Food Chem. 56: 11786-11791.

Mudibu, J., K.K.C. Nkongolo, M. Mehes-Smith and A. Kanlonji-Mbuyi 2011. Genetic analysis of a soybean genetic pool using ISSR markers: Effect of gamma radiation on genetic variability. Plant Breeding Genet. 5: 235-245.

Murtaza, N. 2006. Cotton genetic diversity study by AFLP markers. Electronic Journal of Biotechnology ISSN: 07173458, 9(4), Issue of July 15.

Muse, S.V. and K.J. Liu. 2005. Powermarker: An integrated analysis environment for genetic marker analysis. Bioinformatics. 21: 2128- 2129.

Nemli, S. 2013. Detection of DNA Markers Controlling Some Economically Important Agronomic Characters by Association Mapping in Common Bean (Phaseolus vulgaris L.) - Dissertation, University of Ege, Izmir, Turkey .

Nybom, H. and I.V. Bartish. 2000. Effects of life history traits and sampling strategies on genetic diversity estimates obtained with RAPD markers in plants. Perspect Plant Ecol Evol Syst. 3: 93-114.

Ozturk, Y., S. Aydın, N. Ozturk and K.H.C. Baser. 1996. Effects of extracts from certain Sideritis species on swimming performance in mice. Phytother Res. 10: 70-73.

Ozhatay, N., M. Koyuncu, S. Atay and A. Byfield. 1998. The trade in wild medicinal plants in Turkey. In 'Medicinal plant trade in Europe: conservation and supply', eds Traffic Europe pp. 5-18 - Proceeding of the First International Symposium on the Conservation of Medicinal Plants in Trade in Europe. TRAFFIC Europe, Brussels.

Panahi, B., R. Afzal, M.G. Neghab, M. Mahmoodnia and B. Paymard. 2013. Relationship among AFLP, RAPD marker diversity and Agromorphological traits in safflower (Carthamus tinctorius L.) - Progress in Biological Sci. pp 90-99.

Pecina-Quintero, V., J.L. Anaya-López, A. ZamarripaColmenero, N. Montes-García, C. Nuñez-Colín, J.L. SolisBonilla and et al. 2012. Genetic diversity of sweet sorghum germplasm in Mexico using AFLP and SSR markers. Pesqui Agropecu Bras. 47: 1095-1102.

Pritchard, J.K., M. Stephens and P. Donnelly. 2000. Inference of population structure using multilocus genotype data. Genetics. 155(2): 945-959.

Prohens, J., G.J. Anderson, F.J. Herraiz, G. Bernardello, A. Santos-Guerra, D. Crawford and , F. Nuez. 2007. Genetic diversity and conservation of two endangered eggplant relatives (Solanum verpertilio Aiton, and Solanum lidii Sunding) endemic to the Canary Islands. Genet Resour Crop Evol. 54: 451-464

Qian, X., C-X. Wang and M. Tian. 2013. Genetic diversity and population differentiation of Calanthe tsoongiana, a rare and endemic orchid in China. Int J Mol Sci. 14: 20399-20413.

Rohlf, F.J. 1998. NTSYSpc Numerical Taxonomy and Multivariate Analysis System Version 2.0. User Guide. Applied Biostatistics Inc., Setauket, New York, pp.37.

Ryding, O. 1994. The importance of pericarp structure in the classification of Labiatae. Lamiales Newsletter 3: 1-3.

Saiki, R.K., D.H. Gelfand, S. Stoffel, S.J. Scharf, R. Higuchi, G.T. Horn, K.B. Mullis and H.A. Erlich. 1988. Primerdirected enzymatic amplification of DNA with thermostable DNA polymerase. Science. 239: 487-91.

Shimomura, K. and K. Hirashima, 2006. Development and characterization of simple sequence repeats (SSR) as marker to identify strawberry cultivars (Fragiria $x$ ananassa Duch.). Journal of the Japanese Society for Horticultural Sci. 75(5): 399-402.

Smith, J.S.C., E.C.L. Chin, H. Shu, O.S. Smith, S.J. Wall, M.L. Senior, S.E. Mitchel, S. Resorich and J. Tiegle. 1997. An evaluation of the utility of SSR loci as molecular marker in maize Zea mays): comparisons with data from RFLP and pedigree. Theor Appl Genet. 95: 163-173. 
Strikic, F., D.B. Mavsar, S. Perica, Z. Cmelik, Z. Satovic and B. Javornik. 2010. Genetic variation within the olive (Olea europaea L.) cultivar Oblica detected using amplified fragment length polymorphism (AFLP) markers. African Journal of Biotechnology. 9(20): 2880-2883.

Topcu, G., A.C. Goren, T. Kilic, Y.K. Yildiz and G. Tumen. 2002. Diterpenes from Sideritis trojana. Nat Prod Lett. 16: 33-3.

Vuylsteke, M., R. Mank, R. Antonise, E. Bastiaans, M.L. Senior, C.W. Stuber, A.E. Melchinger and et al. 1999. Two highdensity AFLP $^{\circledR}$ linkage maps of Zea mays L.: analysis of distribution of AFLP markers. Theor Appl Genet. 99: 921935 .
Witkowicz, J., E. Urbanczyk-Wochniak and Z. Przybecki. 2003. AFLP marker polymorphism in cucumber (Cucumis sativus L.) near isogenic lines differing in sex expression. Cell Mol Biol Lett. 8: 857-857.

Yuan, W.J., J.H. Yuan, M.F. Dong and F.D. Shang. 2011. Assessment of genetic diversity and relationships among Osmanthus fragrans cultivars using AFLP markers. Electronic Journal of Biotechnology. ISSN: 0717-3458 http://www.ejbiotechnology.info. doi: 10.2225/vol14-issue1fulltext-9.

Zhang, L., Y-J. Jeon, S-Y. Kang and G-J. Lee. 2012. Genetic Diversity of Natural and Artificial Populations of Model Grass Brachypodium Species Evaluated by AFLP Markers. Hort Environ Biotechnol. 53(2): 143-150. 